\title{
Visualization model design of concept TestBed in Sketch up software
}

\author{
Peter Trebuňa ${ }^{1}$, Marek Mizerák ${ }^{1}$, Jozef Trojan ${ }^{1}$, Ján Kopec ${ }^{1}$ \\ ${ }_{1}$ Technical University of Košice, Faculty of Mechanical Engineering, Institute of \\ Management, Industrial and Digital Engineering \\ Park Komenskeho 9, Košice, Slovakia \\ peter.trebuna@tuke.sk \\ marek.mizerak@tuke.sk \\ jozef.trojan@tuke.sk \\ jan.kopec@tuke.sk
}

\begin{abstract}
This paper deals with the possibility of creating a visualization model or digital twin of a given object in the SketchUp program, which is known for a wide range of modeling applications. This program was chosen because it is the perfect tool for visualizing concepts and is very user-friendly. The application also gives us the freedom to make changes easily, as quickly as possible and much more. The paper also describes the individual elements found in the visualization model and their purpose.
\end{abstract}

\section{Introduction}

Nowadays, I come across the term visualization more and more often. In modern engineering, this concept is inextricably linked to Industry 4.0. Modern manufacturing companies are placing increasing emphasis on creating models of digital companies and the consequent increase in production efficiency, not only from an economic point of view.

It is a digital representation of a physical object or system. The technology behind the digital twin has become so widespread that it includes large items such as buildings, factories, cities, and even people or processes can have digital twins, further expanding the concept. It considers inputs from real-world data about a physical object or system and produces them as predictions of outputs or simulations of how a physical object or system will be affected by those inputs. [1]

Technology allows us to explore and develop new services to meet the changing needs of users and adapt the way they work, live and use technology. [2]

Three-dimensional modeling software and animation programs can be used in different ways for different purposes. They allow you to design your own objects located in space using basic geometric shapes such as spheres, cylinders, cones. All these departments then form the whole scene of projects. Almost every program has a number of tools needed to define their own objects, from two-dimensional images to their conversion into three- 
dimensional form. There is also the ability to model and manipulate basic objects using special tools.

The main topic of this article is the creation of a $3 D$ model of the TestBed concept in SketchUp software.

\section{SketchUp software}

Sketchup, formerly known as Google Sketchup, is an easy-to-use 3D modeling software that provides an extensive database of user-created models. It can be used to sketch or import models to help with all kinds of projects such as furniture construction, video game creation, 3D printing, interior design and more.

SketchUp is an intuitive 3D modeling application that allows you to create and edit 2D and 3D models using the patented "Push and Pull" method. The Push and Pull tool allows designers to print any flat surface into three-dimensional shapes. All you have to do is click on the object and then start dragging it until the user likes what he sees.

SketchUp is a program used for a wide variety of 3D modeling projects, such as architectural design, interior design, landscape architecture, and video game design. The program includes the functionality of the drawing layout, surface rendering and supports third-party add-ons from the Extension Warehouse, the so-called component libraries. SketchUp is also used to create, share, or download 3D models for use with 3D printers. [2]

\subsection{Modeling in SketchUp}

At first we will choose a template in meters. Immediately after selection, the SketchUp workspace will open. The area consists of four main parts, three coordinate axes and a figure. In the upper left corner there is a menu, model name and a button with the option to save the file either on Google Drive or directly to your computer (Figure 1).

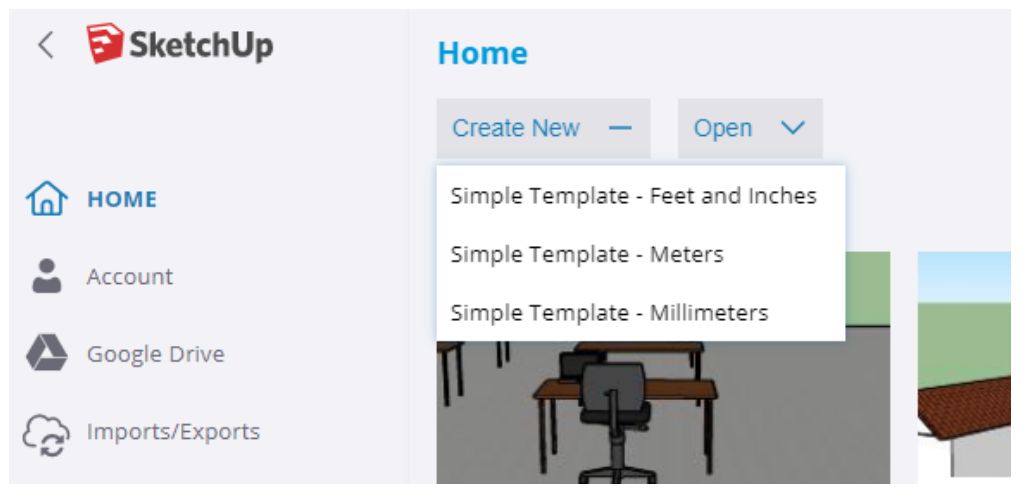

Figure 1 - SketchUp splash screen

On the left side of the desktop is a panel with basic tools. In the lower right corner are the dimensions of the so-called "Measurements", which show us the current dimension of the object. Beginners will welcome the instructor, 
located on the right side of the screen, who helps how to operate the individual tools and also offers valuable keyboard shortcuts (Table 1).

Table 1 - Basic keyboard shortcuts

\begin{tabular}{|c|c|}
\hline Function & Shortcut key \\
\hline Select & Spacer \\
\hline Eraser & E \\
\hline Line & L \\
\hline Arc & R \\
\hline Rectangle & C \\
\hline Circle & P \\
\hline Push/Pull & F \\
\hline Offset & M \\
\hline Move & Q \\
\hline Rotate & S \\
\hline Scale & T \\
\hline Tape Measure Tool & B \\
\hline Paint Bucket & O \\
\hline Orbit & H \\
\hline Pan & Shift + Z \\
\hline Zoom Extents & \\
\hline
\end{tabular}

We started modelling with an area of $320 \mathrm{~m}^{2}$. On the given area there is a test workplace with an area of $250 \mathrm{~m} 2$, an educational room with an area of $60 \mathrm{~m}^{2}$ and an access corridor with an area of $10 \mathrm{~m}^{2}$.

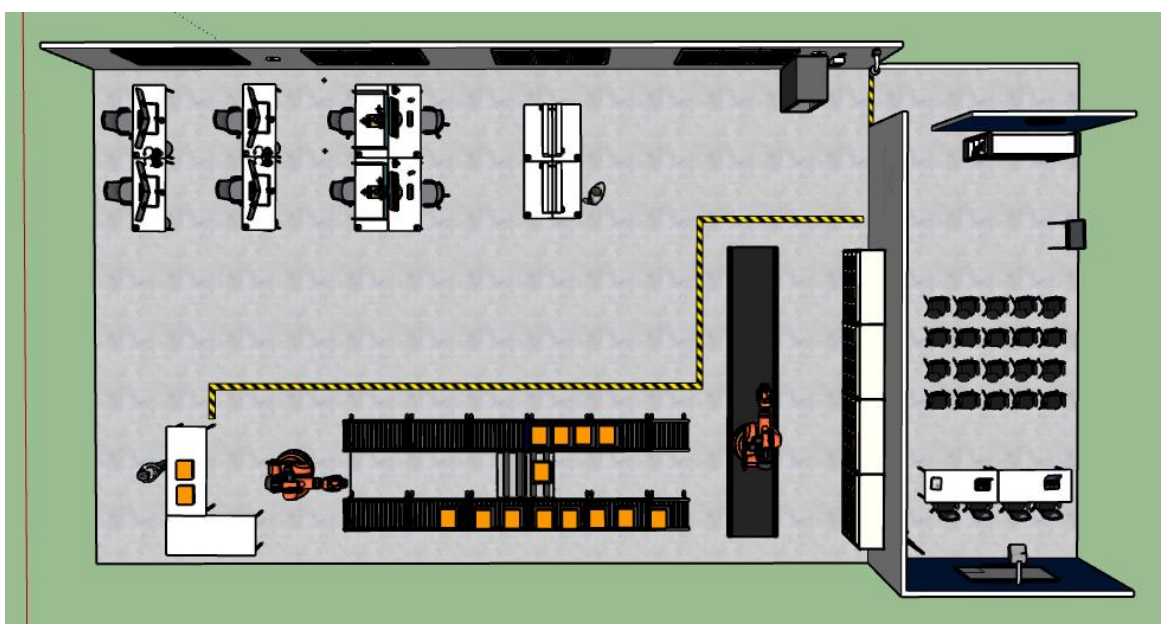

Figure 2 - Testbed Workplace

\subsubsection{Education room}

The educational room provides spaces for interpretation connected with the presentation of the principles and possibilities of Industry 4.0. It is suitable for 
trainings, seminars, workshops, where it is used for lectures or practical exercises not only for students, but also for top management. There is a projector with a board for the presentation and interpretation of the topic, two boards for a deeper explanation of the topic or various drawings. At the back there is a smaller library, which serves to better understand the topic or gain new knowledge, which visitors can use at any time.

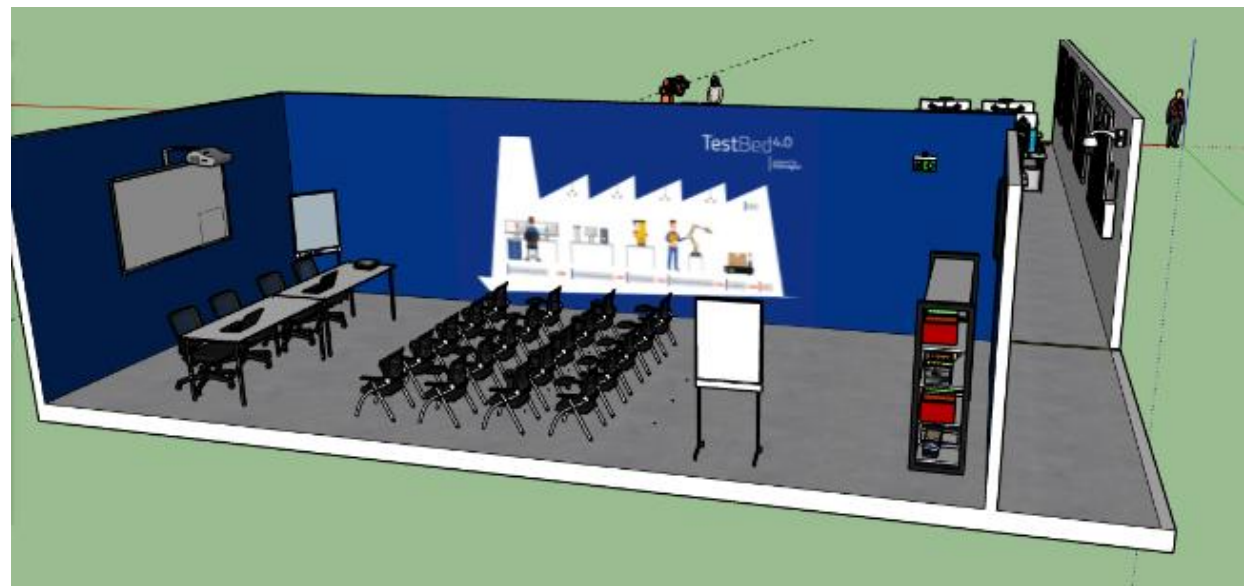

Figure 3 - SketchUp splash screen

\subsubsection{Test workplace - TestBed}

The main room is a test room, which consists of two parts. In the first part there are tables with individual workplaces, where each workplace solves a different function (Figure 4). Each table is marked with a number, which is then assigned to the activity it performs. Individual workplaces are equipped according to the activity they carry out. All elements of the TestBed, ie. computer stations and robots are networked and interconnected.

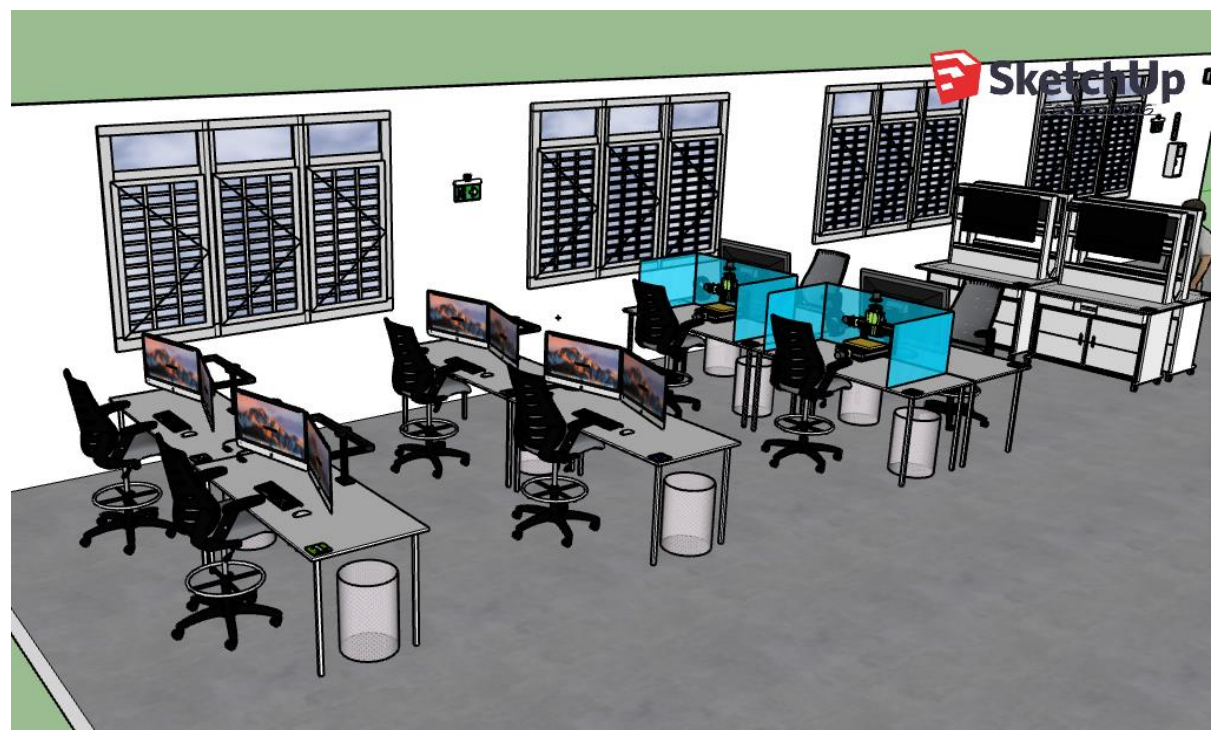

Figure 4 - TestBed with individual workplaces

There are seven workplaces in the area. Workplace number one is in charge of product data collection, where it solves complex and partial integration of business processes, collection, exchange, processing and evaluation of data 
for industrial companies. Workplace number two deals with the development and debugging of automated devices. The pre-production phases are carried out at workplace number three. Workplace number four deals with production, logistics, managerial outputs. Workplace number five has two tables containing CAM machines. On one of them there is a CAM machine designed especially for turning, on the other table there is a CAM machine designed for milling. After entering the input data, resp. parameters of the machine, they can verify the conditions to which the machine tool would be subject in real production. In this way, the efficiency of equipment in manufacturing plants can be tested at this workplace. Workplace number six is in charge of managing the flow of material, equipment and people, safety using RTLS. The RTLS system has the role of the so-called "Trekking", which means monitoring the flow of material, workers and equipment of a production facility, in this case the TestBed workplace. The last workplace is the workplace with the number seven, which consists of four cells designed to apply the concept of the digital twin. Processes such as design, verification and optimization of new processes, workplaces, lines and operations for production and logistics take place there. Design, verification and optimization of production logistics flows of material, routes, use of technology, manpower, packaging quantities. There is also the creation of the concept, cooperation in the development, construction and debugging of production lines and automated equipment for operation in a virtual environment. There is also a verification and optimization of solutions designed by a third party, assembly processes, or production tract.

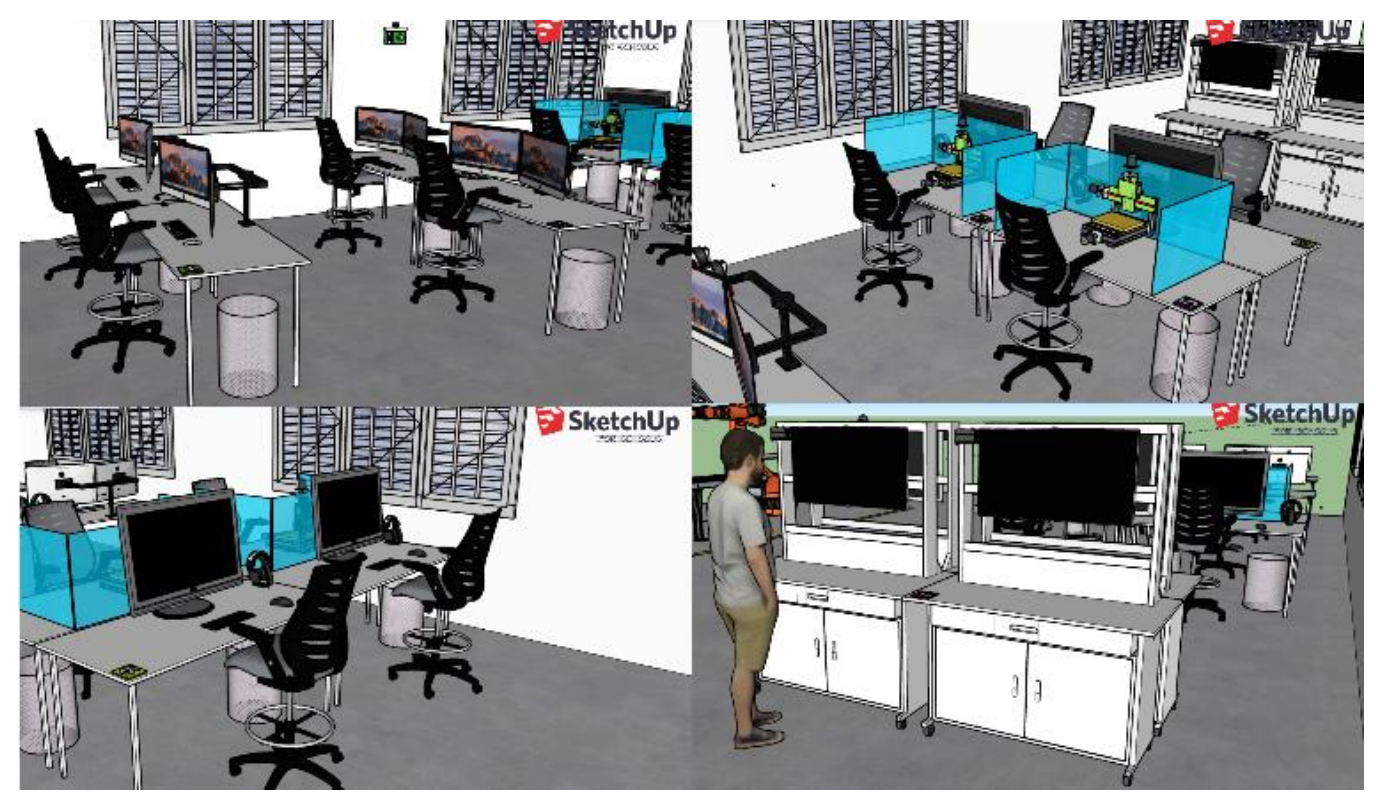

Figure 5 - Working stations

\section{Conclusion}

Digitization has become an integral part of today's world and we are direct witnesses of the industrial engineering sector taking on a new shape. Thanks 
to digitization, a new range of products and services has been created that make work easier for industrial companies.

The main goal of this paper was to create a visualization of the TestBed concept in a computer program for 3D modeling SketchUp, where we briefly introduced the environment. Today's market offers a rich amount of individual software that are designed to create similar visualization models, but one of the reasons why we chose this software is its simple, intuitive operation and the fact that it is not necessary to pay for a license for education.

It is important to mention that the concept of visualization inextricably includes a connection with virtual and mixed reality, which today is experiencing a boom not only in industry but in various areas of life from medicine to the gaming industry. There is a great assumption that this trend will not decline.

\section{Acknowledgement}

This article was created by implementation of the grant projects VEGA 1/0438/20 Interaction of digital technologies to support software and hardware communication of the advanced production system platform, KEGA 001TUKE-4/2020 Modernizing Industrial Engineering education to Develop Existing Training Program Skills in a Specialized Laboratory, APVV-17-0258 Digital engineering elements application in innovation and optimization of production flows, APVV-19-0418 Intelligent solutions to enhance business innovation capability in the process of transforming them into smart businesses

\section{References}

[1] ROSKES, B., DEWITT. B. The SketchUp book: for Version 5. $3^{\text {rd }}$ edition, 2005, West Caldwell, NJ: Conceptual Product Development.

[2] SketchUp blog [online]. Accessible from: https://blog.sketchup.com/products

[3] EDULEARN [online]. Accessible from: https://www.edulearn.com/article/what is revit architecture.html

[4] GRZNAR, P., GREGOR, M., MOZOL, S., KRAJCOVIC, M., DULINA, L., GASO, M., MAJOR, M. A System to Determine the Optimal Work-inProgress Inventory Stored in Interoperation Manufacturing Buffers. Sustainability, 2019, 11(14), 1-36. doi: 10.3390/su11143949.

[5] VINESH, R., KIRAN, F. Reverse Engineering - An Industrial Perspective. London: Springer Science, 2008, ISBN 978-1-84628-855-5.

[6] EDL, M., LERHER, T., ROSI, B. Energy efficiency model for the mini-load automated storage and retrieval systems. International Journal of Advanced Manufacturing Technology, 2013, 1-19. ISSN: 0268-3768.

[7] STRAKA, M., LENORT, R., KHOURI, S., FELIKS, J. Design of large-scale logistics systems using computer simulation hierarchic structure. International Journal of Simulation Modelling, 2018, 17(1), 105-118. 